International Journal of Managing Value and Supply Chains (IJMVSC) Vol. 4, No. 1, March 2013

\title{
An Approach to Identify Failure Factors of Enterprise Application Implementation in Indian Micro Enterprises
}

\author{
* Rana Basu \\ School of Engineering Entrepreneurship \\ Indian Institute of Technology, Kharagpur, India \\ Dhrubes Biswas \\ School of Engineering Entrepreneurship \\ Indian Institute of Technology, Kharagpur, India \\ *Corresponding Author Email: rbasu004@gmail.com
}

\begin{abstract}
Enterprise Business Application or in other words ERP can be regarded as a novel business solution. Today organizations of any magnitude are implementing and some are in the process of implementing such Enterprise Information System. Implementation of Enterprise Business Application is quite difficult and complex process and has been subjected to substantial research. As cases of ERP failures have increased many researches have been carried out to identify which issues can lead to implementation successful. It has been observed while compiling the literature that majority of the previous studies and research projects have been conducted in identifying the critical success factors rather than critical failure factors. From the literature it has been observed that most of the developed countries had been reaping the benefits of enterprise application integration since long time and because of its advantages now a day developing countries too are embracing such technology integration. Developing countries which mostly tackle with unique challenges have a diverse condition from the implicit assumptions of leading countries. India being one of these countries that many of its Information Technology implementation failures take place. Micro small and medium enterprises (MSME) can be considered as vital part of the Indian economy contributing over $45 \%$ of industrial production and around $40 \%$ of the total exports. As per International Data Corporation $(I D C)$ the awareness and the rate of adoption of ERP are highest among large organizations but it is the MSMEs that would fuel the future growth. In India there is a big market for ERP for MSMES, given that there are over 20,000 small and mid size industries. Identifying the critical success factors of Enterprise Application implementation have been subjected to substantial in-depth research, however while going through the literature it seems as such there is no comprehensive study has taken place that identifies the critical failure factors of Enterprise Application implementation in context to Indian micro enterprises. The purpose of this paper is to present the findings of a study which is based on the results of a comprehensive compilation of literature and subsequent analysis of ERP implementation failure factors in context to Indian Micro, Small and Medium scale Enterprises (MSMEs). This paper attempts to empirically assess which factors are most critical in the ERP implementation process from the perspective of the Indian MSMEs.
\end{abstract}

Keywords: $E R P, M S M E$, factors, Risk, Factor analysis, $P C A$

\section{Introduction}

Organizations of any magnitude in developing countries have implemented and some are in the stages of implementing Enterprise Business Application in order to capture its benefit. An example of Enterprise Business Application is nothing but ERP (Enterprise Resource Planning).

DOI: $10.5121 /$ ijmvsc.2013.4104 
ERP system can be regarded as a novel integrated software solution which is being typically offered by vendor as package that support seamless flow of information flowing through the company (Davenport, 1998). Today in this competitive business scenario ERP are increasingly becoming accepted platform for the micro small and medium scale sectors and is viewed as one of the ways to achieve competitive advantage and to reengineer business process (Gable and Stewart, 1999) and can be considered as enterprise backbone of organization (Nah et al., 2001). Over the past few years, global economic downturn has put some spotlight on many business organizations of any magnitude. Indian small and medium businesses were also affected with such scenario. However, the large establishments have attempted to tackle in their own way and it is the small and the medium scale enterprises (SME) that are showing their huge potential growth (Koh et al., 2007, Deep et al., 2008, Helo, 2008).

The time now has come for micro small and medium scale enterprises (MSME) to build up on their inherent strength and to expand and compete the global market. The MSME sector today can be considered as vital part of the Indian economy contributing over $45 \%$ of industrial production and around $40 \%$ of the total exports. In India there are around thirteen million MSMEs and employing around 31 million employment opportunities and can be considered as the single largest generation in terms of employment generation in the manufacturing sector. This research study specifically targeted the Indian MSMEs. Like China, India is also emerging as a major manufacturing hub in this era of global supply chains as well as becoming a part of global economy. As per International Data Corporation (IDC) the awareness and the rate of adoption of ERP are highest among large organizations but it is the MSMEs that would fuel the future growth. In India there is a big market for ERP for SMEs, given that there are over 20,000 small and mid size industries. Today ERP packages are exceedingly valuable in integrating a global business and provide a "common language" throughout the organizations. Some of the noted benefits that the organizations enjoy after implementing ERP are: Increase efficiency in overall business, improved decision and planning, better resource utilization, improvement in labor productivity, organizational empowerment, Improvement in financial management, improved flexibility in information generation.

To implement Enterprise Business Application in an organization is generally quite difficult. However implementing such system is much complex and expensive. It has been found that organizations inspite of spending high price on ERP implementation process have not been able to achieve true benefits out of it. Despite the popularity of ERP the failure rate of its implementation remains high. As per the reports it has been estimated that Enterprise based IT solutions failure rate remain in the 67\% $-90 \%$ range (Cologero, 2000). Some surveys show that failure as an integral part of ERP implementation and as such success cannot be achieved even in desirable situation also. A number of publications have highlighted the failures and frustrations that the organizations had to go through while implementing ERP system. A study being carried out by Gartner group and some American companies found that $32 \%$ of the Enterprise Business Application (i.e. ERP) was delivered late and the organizations were not able to reap the true benefits of implementation. Today ERP implementation has been subjected to substantial research. As cases of ERP failures have increased many researches have been carried out to identify which issues can lead to implementation successful. As the failure rate is increasing day by day so the question automatically arises what are those issues responsible for unsuccessful implementation of ERP. If those failure issues are identified and controlled then it can be expected that the implementation of enterprise business application becomes successful. This paper attempts to explore such issues that would lead to implementation of ERP unsuccessful, with the view that if such issues are given attention and controlled then it would lead to the implementation of ERP a successful one. 
International Journal of Managing Value and Supply Chains (IJMVSC) Vol. 4, No. 1, March 2013

\section{Literature Review}

There have been reports on unsuccessful implementations of Enterprise resource planning within business including those of the Hershey cases, Nike losing shoe orders, FoxMeyer's drug processing order failures (Scott and Vessey, 2002). Further it is also reported that $70 \%$ of the ERP implementations did not achieve

their targeted benefits (Majed, 2000). From the literature and several cases the implementations of Enterprise application that can be classified as "failures" ranges from $40 \%$ to $60 \%$ or higher (Langenwalter, 2000) and thus the implementation projects lead to problems which is as serious as organizational bankruptcy (Bulkelery, 1996; Davenport, 1998; Markus et al., 2000). From the organizational perspective failure can be defined as an implementation that cannot able to fetch sufficient return on investment (ROI) as being identified in the project approval phase. From the definition as mentioned it is being found that failure rates are in the range of $60 \%-90 \%$ (Ptak, 2000, Harvard, 2007 and Leung, 2008).

The research report estimation by Standish Group International reveals that 90 percent SAP R/3 projects run late (Scott and Vessey, 2002) as also Williamson (1997) indicated that 3/4 ERP projects were considered as failure and thus cannot be accepted. Some researchers also proposed that the concept of risk pertaining to Enterprise application may be the reason (Wright and Wright, 2001).

In an attempt to adopt a suitable research methodology, the following observations were made while doing the review of literature. This section tries to explore the critical failure factors affecting ERP implementation. It has been observed from the recent survey as per the opinion and views of Information technology managers and identified three primary reasons for failure in ERP projects: improper plan (cited by 77 percent) changing goals and objectives during implementation (cited by 75 percent) and lacking of proper management support ( 73 percent). Critical Failure Factors are the prime and key areas "where things must go wrong" in order to implement ERP implementation to achieve high level of success. In other way failures can also be defined like exceeding budget, lagging behind the project schedule, and also of failing to match expectations.

Researchers are of the opinion that identifying the risk management factors for Enterprise Application Implementation can be confront for project managers as well as small business entrepreneurs as there are unusual ways in which way they can be categorized (Baccarini, 2004).

Boehm (1991) thought IT system project failures are caused by certain failure factors which includes: personnel shortage, impractical budget and plan, improper software and users' interface, gaudy functions, and unsteady demands.

On the basis of interview with the senior management involved in implementation process of ERP system identified some risk factors for ERP implementation which are: inadequate training, shortage of expert, lack of information flow within organization, failure of synergizing inside and outside expertise, business plan and vision not aligning with the ERP function, and separation from certain ready systems (Wright and Wright, 2001).

Huang et al. (2004) on the basis of research study proposed some risk factors for ERP projects which are: insufficient support from top management, no proper client communication, no proper training facilities for end - users, shortage of user's support, lacking project management, intention to integrate fully with existing system, conflict in business, improper structure of ERP team, failure in proper Business process reengineering, misunderstanding the demand for change. 
International Journal of Managing Value and Supply Chains (IJMVSC) Vol. 4, No. 1, March 2013

There are four primary reasons that ERP implementation fails, they are: inadequate training and education, poor leadership and support from top management, resistance to change and unrealistic expectation for benefits (Tapp et al, 2003).

It has been found some generalized risk factors for software projects can be as follows: unwillingness of the client in participation, the need for vast clients and relevant personnel involved, too broad coverage of business, the system lacking clear targets, deficiency in reducing the system's effect to business, shortage of support and experience, technological or cost-profit problems. Alter deemed such factors impeded the successful application of software (Alter, 1979).

Ganesh L and Arpita Mehta (2010) on the basis of research study identified and validated some of the crucial failure factors affecting ERP implementation in context to Indian small and medium scale enterprises which include: Poor quality of testing, Unrealistic expectations from top management, poor top management support, poor consultant effectiveness, users resistance to change, software modification, functionality problem with system, poor project management, unclear concept about ERP system, poor quality of BPR, poor IT infrastructure, high turnover rate, informal strategy.

\section{Research Methodology and Objective}

There are certain factors in context to implementation of ERP projects. This study attempts the critical failure factors with the objective that if such factors are taken into careful attention and subject to control then it would lead such information systems successful. The research steps including identifying ERP failure factors, conducting semi-structures interview, instrument development, data collection and data analysis using exploratory factor analysis.

As observed from the previous literature surveys there are different issues responsible for negative implementation of ERP. The content validity of these construct was tentatively established by extensive review with top executives and other stakeholders. Some items were removed from the construct if their removal results in an increase in reliability estimates. By doing extensive review of literature some failure factors affecting ERP implementation have been identified. Few of them found to be inapplicable in context to MSMEs in India. Further investigations and from the questionnaire survey revealed 15 most influencing risk issues affecting Enterprise Business Application. The important risk factors affecting ERP implementation are: Poor top management support, Poor project management, Poor quality of testing, Poor quality of BPR, Poor IT infrastructure, Poor knowledge transfer, Lack of proper communication, Poor consultant effectiveness, ERP software misfit, Users resistance to change, High turnover rate of project team members, Part time dedication, Functionality problems with system, Cost overruns, Over reliance for high customization.

\section{Survey Methodology and Semi Structured Interview}

In order to explore the more cited Enterprise application failure issues the researchers have conducted an in-depth review on current literature that might have not been well documented in available research works. In addition to this there also exist some other factors in special contexts, cultures, economies, etc. For conducting a holistic analysis on enterprise application failure factors the researchers adopted both literature review and interviews.

The researchers identified those MSMEs which have recently gone through the implementation process of ERP in their respective organizations. The participants were asked to indicate their perception on a Likert scale (1-5) with response ranging from "strongly disagree" to "strongly 
agree". These five item scales were empirically tested and validated. Questionnaire survey method was adapted from previous from previous literature and studies (Ajayi et. al, 2007). The main reason for referring to literature when developing a questionnaire is to ensure high reliability and validity of the survey. The face or content validity of the questionnaire is being conducted through the literature review as well as experts judgement. In order to ensure this at first IT/ERP project officers with high academic background having more than five years of experience reviewed the questionnaire. They had their comments particularly on the length and clarity of the questionnaire. The content validity of the said questionnaire was thereby addressed. Their suggestion was incorporated in the final version of the questionnaire. For each of these issues, a number of elements or statements were formulated through the definition and description of each one in the literature.

\section{Data Collection Procedure}

The first phase involves comprehensive compilation of literature and searching of prime Management Information System (MIS) journals that the researcher could access. With this some conference papers, doctoral theses were also accessed. Furthermore the databases like Emerald, Springer, Proquest, Science Direct, Jstor etc. were also searched.

The second phase of data collection is the questionnaire survey from the targeted organizations. The researchers contacted those MSMEs that are relevant for the study. Some of the leading vendors were also contacted who provided the list of users, where they have implemented ERP and they also assisted in collecting data by forwarding the questionnaire on behalf of the researcher. Overall 85 responses were obtained for analysis representing wide variety of industries.

\section{Data Analysis and Results}

The research study presented here is exploratory in nature which identifies 15 most influential risk factors for the failure of implementation of Enterprise Business Application. Researchers in this study used SPSS V.17 in order to analyze the data obtained from the survey. The obtained data on failure factors were further subjected to checking to see whether the data could be analyzed using factor analysis. It is found from the analysis that the correlations were high among the factors as well as Bartlett's test of sphericity is found be significant $(p<0.05)$ which shows the acceptability of the data. Then we proceed for Shapiro- Wilk test to determine whether our sample had normal distribution and we found that none of the variables are normally distributed so data thus found to be suitable to carry out factor analysis. In this case Principal Component Analysis being our choice for the factor extraction method as proposed in Exploratory Factor Analysis. Here in this research study exploratory factor analysis was conducted on the different measures to purify the instrument and to validate the various dimensions implementation at Indian MSMEs.

Factor Analysis has been performed on explanatory variables with the objective to determine the minimum number of factors that account for maximum variance in data (Kim and Muller, 1987; Hair et al, 1987). The Table 1 below summarizes the proportion of each factors variance explained by other factors. 
International Journal of Managing Value and Supply Chains (IJMVSC) Vol. 4, No. 1, March 2013

Table I

\section{Communalities}

\begin{tabular}{|l|r|r|}
\hline & Initial & Extraction \\
\hline poor top mgmt support & 1.000 & .815 \\
poor project management & 1.000 & .887 \\
poor quality of testing & 1.000 & .797 \\
poor quality of BPR & 1.000 & .836 \\
poor IT infrastructure & 1.000 & .730 \\
poor knowledge transfer & 1.000 & .706 \\
lack of proper communication & 1.000 & .871 \\
poor consultant effectiveness & 1.000 & .828 \\
ERP software misfit & 1.000 & .905 \\
users resistance to change & 1.000 & .570 \\
high turnover rate & 1.000 & .839 \\
part time dedication & 1.000 & .829 \\
functionality problem & 1.000 & .774 \\
cost overruns & 1.000 & .713 \\
over reliance for high customization & 1.000 & .778 \\
\hline
\end{tabular}

Extraction Method: Principal Component Analysis.

The researchers adopted the method of principle components as the extraction techniques and the rotation method was varimax. In this study Kaiser Criterion (Kaiser, 1960), has been followed which suggests selection of those factors whose Eigen value is greater than 1. From the Table 2 Total Variance Explained it shows cumulative variance of $79.19 \%$ which means that good factor analysis has been done. The factor analysis has been done on 15 items which results into the extraction of 6 components.

Table II

\section{Total Variance Explained}

\begin{tabular}{|c|c|c|c|c|c|c|c|c|c|}
\hline \multirow[b]{2}{*}{ Component } & \multicolumn{3}{|c|}{ Initial Eigonvaluos } & \multicolumn{3}{|c|}{ Extraction Sums of Squarod Loadings } & \multicolumn{3}{|c|}{ Rotation Sums of Squarod Loadings } \\
\hline & Total & $\%$ of Variance & Cumulative $\%$ & Total & $\%$ of Veriance & Cumulative $\%$ & Total & $\%$ ofvariance & Cumulative $*$ \\
\hline 1 & 4.963 & 27.920 & 27,020 & 4.053 & 27.020 & 27.020 & 2.775 & $1 \mathrm{a} .501$ & 18.501 \\
\hline 2 & 2472 & 16.479 & 43.499 & 2472 & 16.479 & 43.499 & 2,483 & 16.555 & 35.056 \\
\hline 3 & 1.889 & 12.590 & 56.090 & 1.889 & 12.590 & 56.090 & 1.884 & 12.562 & 47.618 \\
\hline 4 & 1.306 & 8.708 & 64.797 & 1.306 & 8.708 & 64.797 & 1.813 & 12.084 & 59.703 \\
\hline 5 & 1.124 & 7.494 & 72.291 & 1.124 & 7.494 & 72291 & 1.541 & 10.272 & 69. 375 \\
\hline a & 1.036 & 3.907 & 79,198 & 1.036 & 5.907 & 79.198 & 1.383 & 9.223 & 79.198 \\
\hline 7 & 755 & 5.031 & $8+229$ & & & & & & \\
\hline 8 & s55 & 3.698 & 87.928 & & & & & & \\
\hline 9 & .450 & 3.970 & 90.998 & & & & & & \\
\hline 10 & .396 & 2.341 & 93.639 & & & & & & \\
\hline 11 & .348 & 2.322 & 95.961 & & & & & & \\
\hline 12 & .311 & 2.974 & 98.035 & & & & & & \\
\hline 13 & .129 & मूิ3 & 488.898 & & & & & & \\
\hline 14 & .096 & .537 & 99,535 & & & & & & \\
\hline 15 & .070 & .465 & 100,000 & & & & & & \\
\hline
\end{tabular}

Extraction Method: Principal Component Analysis. 
Factor loading is a simple correlation between the factors and the variables. The best way of getting the judgement is rotated factor matrix. Rotation is a method which simplifies the interpretation of factor analysis. Varimax is one of the most popular orthogonal rotations, which aims to maximize the variance of squared loadings on a factor to produce some high and low loadings for each factor (Kim and Muller, 1978). Table III. below summarizes the results of factors identified of orthogonal rotation.

Table III

ROTATED COMPONENT MATRIX

Rotated Component Matrix ${ }^{a}$

\begin{tabular}{|c|c|c|c|c|c|c|}
\hline & \multicolumn{6}{|c|}{ Component } \\
\hline & 1 & 2 & 3 & 4 & 5 & 6 \\
\hline poor top mgmt support & .208 & .043 & .249 & .448 & .383 & .600 \\
\hline poor project management & .820 & -.043 & .378 & .237 & .055 & -.102 \\
\hline poor quality of tes ting & .848 & -.034 & .268 & -.070 & -.025 & .007 \\
\hline poor quality of BPR & -.031 & .048 & -.134 & .035 & .901 & -.036 \\
\hline poor IT infras tructure & -.442 & 655 & .183 & -.184 & -.112 & -.159 \\
\hline poor knowledge transfer & .471 & .579 & .297 & .216 & -.122 & .011 \\
\hline $\begin{array}{l}\text { lack of proper } \\
\text { comm unication }\end{array}$ & .185 & .024 & -.177 & .891 & -.106 & -.024 \\
\hline $\begin{array}{l}\text { poor consultant } \\
\text { effectiveness }\end{array}$ & 142 & .863 & -.044 & -.089 & .148 & .174 \\
\hline ERP software misfit & .775 & .437 & -.222 & .150 & .200 & .048 \\
\hline $\begin{array}{l}\text { users resistance to } \\
\text { change }\end{array}$ & .431 & .132 & .227 & .175 & .533 & -.005 \\
\hline high turnover rate & -.087 & -.112 & -.099 & .027 & -.105 & .893 \\
\hline part time dedication & -.006 & -.077 & .119 & .776 & .407 & .202 \\
\hline functionality problem & .064 & .831 & .093 & .072 & .085 & -.241 \\
\hline cost overruns & .237 & .218 & .755 & -.081 & .064 & .171 \\
\hline $\begin{array}{l}\text { over reliance for high } \\
\text { customization }\end{array}$ & .121 & .005 & .855 & .001 & -.072 & -.165 \\
\hline
\end{tabular}

Extraction Method: Principal Component Analysis.

Rotation Method: Varimax with Kaiser Normalization

a. Rotation converged in 7 iterations.

The rotation minimizes the number of variables having higher correlations on factor. As the rotation is orthogonal the resulting factors will be uncorrelated. In the rotated factor the variables with higher factor loading is considered as most important. Thus from the Table 3 the most influencing risk factors affecting Enterprise Business Application at Indian MSMEs are: Poor quality of testing, Poor consultant effectiveness, Overreliance for high customization, Lack of proper communication, Poor quality of BPR, High turnover rate.

For reliability analysis Chronbach's alpha has been calculated. In our study Chronbach's alpha is 0.752, which is well above the minimum suggested level as suggested by Hair et al. (1998) and thus this validates our study. The validity was found by applying Guilford's formula. For the group of 85 respondents from various industry sectors the validity was found to be 0.8671 .

Results: In our study and as per higher factor loading the most influencing risk factors affecting the implementation of Enterprise Application in Indian MSMEs are prioritized below:

Table IV Prioritizing the Factors

\begin{tabular}{|c|c|}
\hline Factors & Priority \\
\hline Poor quality of testing & 6 \\
\hline Poor consultant effectiveness & 4 \\
\hline Overreliance for high customization & 5 \\
\hline Lack of proper communication & 3 \\
\hline Poor quality of BPR & 1 \\
\hline High turnover rate & 2 \\
\hline
\end{tabular}




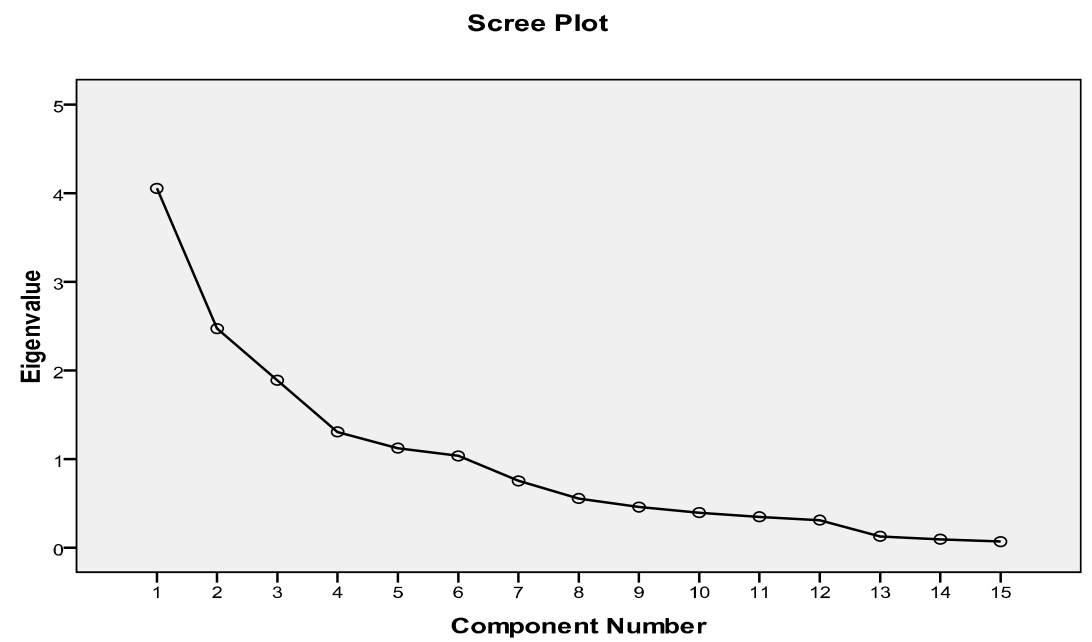

Fig 1. Result of Eigen values for 15 items

\section{Discussion}

Based on the above findings this study provides a partial support for the explanation of factors leading to unsuccessful implementation of Enterprise Business Application. In this section some deliberations have been put forward as a guideline to the ERP consultants, ERP vendors and entrepreneurs so that in future they can change their implementation approach to avoid the future failure of enterprise application implementation in Indian SMEs as well as in MSMEs.

Poor Quality of BPR: One of the most important factors for successful implementation of Enterprise Application is proper business process reengineering (BPR). Aligning the business processes to the Enterprise Application is critical (Holland et al., 1999; Sumner, 1999). Thus it is recommended to avoid insufficient and poor quality of business process reengineering that leads to the failure of implementation process in Indian organizations.

High Turnover Rate: Such high turnover rate of Enterprise Application team members should be avoided as such lead to implementation failure one because of the loss of trained resource. While going through the literature survey and case studies it is found that project team members suffered from high work stress while coping up with the implementation phase. This condition lead to insufficient knowledge transfer among the project team members during the ERP life cycle.

Lack of proper communication: Effective communication is critical to Enterprise Application implementation (Falkowski et al., 1998). Promotion of project team members and the advertisement of the project progress to the rest of organizations depend on proper and effective communication (Wee, 2000). Thus lack of proper communication leads to confusion and misunderstanding for the successful implementation process and thus leads to failure, hence should be avoided.

Poor consultant effectiveness: Proper and effective role of consultants can be regarded as one of the most important issues towards successful implementation of Enterprise Business Application. The responsibility of the consultants is to ensure proper distribution and handling of data as well as to restructure organizational hierarchies in order to align ERP systems and 
corporate requirements. Thus it is sure that poor consultant's effectiveness would lead to failure in implementation.

Overreliance for high customization: It is recommended to avoid over realization on heavy customization. Overreliance on high customization results increase in complexity and cost and thus leads to implementation failure.

Poor quality of testing: Poor quality of testing not only waste time and money but also leads to implementation of Enterprise Business Application an unsuccessful one. Thus organizations of any magnitude are recommended to avoid poor quality of testing.

\section{Conclusion}

India has more than 35 million MSMEs according to various industry estimates. Although MSMEs form the backbone of India's economy, the technological advancement or development of this segment has been slow. There is absence of a business continuity model support system in case of any unforeseen contingency and such limitations have affected the MSMEs repeatedly. With exposure to global economies, customers' preferences are changing drastically and accordingly, organizations need to enhance their products and services. Internally, within the organizations, they need to take care of risks due to employee churn, data security against competition, copyright protection, duplication of data, silos of applications and data etc.

The failure rate of the implementation of ERP systems in India is very high, due to inappropriate introduction and implementation. In this research we found some critical problems of implementation of ERP systems, which can induce the suggestions of improvement strategies for the industries as well. It is believed that if organizations take suitable improvement actions the effectiveness and quality of service of ERP systems can be raised. As a result industries will improve the success rate of ERP implementation. The researchers believe that the outcome of the results will be beneficial for the organization which wishes to implement such Enterprise Business Applications (i.e. ERP). This study provides a partial support for the explanation of failure while implementing Enterprise Information System. The results showing the risk issues in this research study would help the implementers so that no disruption occurs in implementing the systems in future. If the identified risk factors are being controlled then it would lead to implementation successful.

This research study has got some limitation that is it is specifically targeted to Indian MSMEs. Beside the issues as identified there may be other issues too need to be explored. There is also a scope to enhance this study by extending the number of respondents and taking more number of industries into consideration.

\section{References:}

Ajayi, I. A. and Omirin, Fadekemi F. (2007). "The Use of Management Information Systems (MIS) In Decision Making In the South-West Nigerian Banks". Educational Research and Review, 2 (5), 109-116.

Alter, S. (1979), "Implementation risk analysis", TIMS Studies in Management Sciences, Vol. 13 No. 2, pp. 103-19.

Boehm, B. W. (1991), "Software Risk Management: Principle and Practices," IEEE Software, Vol. 8, No. 1, pp. 32-41

Bulkelery, W.M. (1996) A cautionary network tale: Fox-Meyer's high-tech gamble. Wall Street Journal Interactive Edition 
International Journal of Managing Value and Supply Chains (IJMVSC) Vol. 4, No. 1, March 2013

Cotteleer, M.J. (2002), ERP: Payoffs and Pitfalls. Harvard Business School Working Knowledge, http://hbswk.hbs.edu/item.jhtml?id=3141\&t=operations

D. Baccarini, G.S. Salm, P.E.D. Love (2004)., "Management of risk in information technology projects", Industrial Management \& Data Systems 104 (4), pp. 286-295.

Davenport, T.H (1998) Putting the Enterprise into the Enterprise System. Harvard Business Review, Vol. 76, Issue 4, pp.121 - 131

Gable, G. \& Stewart, G. (1999), "SAP R/3 implementation issues for small to medium Enterprises", Proceedings of the 5th Americas Conference on Information Systems, Milwaukee, WI, 779-781.

Hair, J., Black, W., Babin, B., Anderson, R., \& Tatham, R. (1998). Multivariate Data Analysis, $6^{\text {th }}$ ed., New Jersey: Pearson Prentice Hall.

Harvard, N., (2007). Statistics/Research on ERPs. Retrieved 04 November 2008, from http://erp.ittoolbox.com/groups/strategy-planning/erp project management/statisticsresearch-onerps1582241\#

Holland, P., Light, B. and Gibson, N., (1999) . "A critical success factors model for enterprise resource planning implementation ", Proceedings of the 7th European Conference on Information Systems, Vol 1, pp. 273-97.

Kaiser, H.F. (1960). "The Application of Electronic Computers to Factor Analysis", Educational and Psychological Measurement, 10 (1), 141-151.

Kim, J.-O., \& Mueller, C.W. (1978). Factor analysis: Statistical methods and practical issues. Beverly Hills, CA: Sage.

L., Ganesh and Mehta, Arpita (2010),"Critical Failure Factors in Enterprise Resource Planning Implementation at Indian SMEs", Asian Journal of Management Research, Vol.1, No. 1, pp.44-57

Langenwalter, G. (2000) Enterprise Resources Planning and Beyond: Integrating Your Entire Organization. St. Lucie Press, Boca Raton, FL.

Leung, C., (2008). ERP Implementation Failure Rate. Retrieved 25 September 2008, from http://wizebiz.ca/blog/2008/04/05/erp-implementation-failure-rate/

Majed, A. (2000) Enterprise-Wide Information Systems: The Case of SAP R/3 Application. In Proceedings of the Second International Conference on Enterprise Information Systems, pp 3-8.

Markus, L., Axline, S., Petrie, D., and Tanis, C. (2000) Learning from Adopters' Experience with ERP Problems Encountered and Success Achieved. Journal of Information Technology 15(2), pp 245-265.

Nah, F.F.H., Lau, J.L.S., and Kuang, J (2001) “Critical Factors for Successful Implementation of Enterprise Systems”, Business Process Management Journal, Vol. 7 Issue 3, pp. 285 - 296

Ptak, C. (2000) ERP: Tools, Techniques, and Applications for Integrating the Supply Chain. St. Lucie Press, Boca Raton, FL.

Scott, J.E. and Vessey, I. (2002), "Managing risks in enterprise systems implementations", Communication of the ACM, Vol. 45 No. 4, pp. 74-81.

Shi-Ming Huang, I-Chu Chang, Shing-Han Li, Ming-Tong Lin, (2004) "Assessing risk in ERP projects: identify and prioritize the factors", Industrial Management \& Data Systems, Vol. 104 Iss: 8, pp.681 - 688

Sumner, M. (1999). Critical success factors in enterprise wide information management systems projects. Proceedings of the Americas Conference on Information Systems, Milwaukee, WI, pp. 232-234.

Tapp, R. M., Hesseldenz, J., \& Kelley, G. (2003). The Role of Project Acceptance in the Successful PeopleSoft Human Resources Management System Implementation for the Kentucky Community an Technical College System, Ninth Americas Conference on Information Systems, 1380-1388 
International Journal of Managing Value and Supply Chains (IJMVSC) Vol. 4, No. 1, March 2013

Wee, S. (2000). Juggling toward ERP success: Keep key success factors high, ERP News. Retrieved June 1, 2000, from http//www.erpnews.com/erp904/02get.html

Wright, S. and Wright, A.M. (2001), "Information system assurance for enterprise resource planning systems: implementation and unique risk considerations", Journal of Information Systems, Vol. 16, pp. 515.

Wright Sally, Wright Arnold M (2002). "Information system assurance for Enterprise Resource planning systems: unique risk considerations”, Journal of Information Sciences, Vol. 16, pp 99-113. 